\title{
Correlation of Glycemic Status with Plasma Fibrinogen Level in Insulin Dependent as Well as Noninsulin Dependent Diabetic Patients
}

\author{
Shamim Shaikh Mohiuddin* \\ Assistant Professor, Department of Biochemistry, College of Medicine, Imam Abdulrahman Bin Faisal University, Dammam, Kingdom of \\ Saudi Arabia.
}

Received: September 19,2018; Accepted: September 28,2018; Published: October 02,2018

*Corresponding author : Shamim Shaikh Mohiuddin, Department of Biochemistry, College of Medicine. Imam Abdulrahman Bin Faisal University, PO box1982, Dammam- 31441, Kingdom of Saudi Arabia, Email: smohiuddin@iau.edu.sa

\begin{abstract}
Aims and objective: Fibrinogen is an indicator of an inflammatory vascular changes and endothelial dysfunction. It has been identified as an independent risk factor for cardiovascular disease and it is closely associated with traditional cardiovascular risk factors. Diabetic patients have higher cardiovascular morbidity than non -diabetic individuals. Patients with diabetes mellitus have 2 to 4 times increased risk for cardiovascular disease than non-diabetic patients. Several studies have shown that haemostatic factor especially hyperfibrinogenemia is implicated as a source of atherosclerotic changes and its complications. Fibrinogen which is an acute phase protein plays a key role in the pathogenesis of atherosclerosis and complication of atherothombosis disease. Pathogenesis of noninsulin dependent diabetes mellitus (NIDDM), widely known as type 2 diabetes is observed to closely relate with acute phase response which is predominately cytokine mediated. The role of inflammation in insulin dependent type 1 diabetes (IDDM) is still contradictory. By estimating circulating fibrinogen in NIDDM and IDDM patients, we tried to establish this hypothesis.
\end{abstract}

Methods: Freshly diagnosed twelve IDDM cases, twenty-five NIDDM cases and twenty-five NIDDM cases under oral hypoglycemic agent for at least 5 years were selected for this study and were estimated their glycemic status and the level of fibrinogen. Thirty normal controls were also selected.

Results: Freshly diagnosed IDDM and NIDDM cases showed significantly higher levels of the fibrinogen in compare to control. Plasma fibrinogen was higher and had positive correlation with increased duration of diabetes. NIDDM cases had slightly elevated values of fibrinogen in compared to the IDDM cases. There are no significant change of fibrinogen level is found in NIDDM cases after treating by oral hypoglycemic drugs for at least 5years in compare of freshly diagnosed NIDDM cases.

Conclusion: By evaluating the plasma level of fibrinogen in different categories it can be postulated that NIDDM patients had a higher plasma fibrinogen level in compare to control. Fibrinogen level was significantly correlated with glycemic control. This line of pathological basis should be further explored for diagnosis, management and follow up.

Key words: NIDDM; IDDM; fibrinogen; glycemic status; low grade chronic inflammation

\section{Introduction}

Diabetes mellitus is the most common metabolic disorder characterized by metabolic abnormalities and long term complications. The chronic complications of diabetes mellitus affect many organ systems and are responsible for the majority of morbidity and mortality associated with the disease [1]. The worldwide prevalence of diabetes mellitus has been increased dramatically over the past two decades and the prevalence of noninsulin dependent diabetes mellitus (NIDDM) is expected to rise more rapidly in future because of increasing obesity and reduced activity levels. In the past decade; the potential role of hemostatic factors; particularly fibrinogen; in atherosclerosis and its complications has generated considerable attention. Studies have shown that most common precipitating factor of acute myocardial infarction is formation of an occlusive thrombus; on a damaged atherosclerotic lesion. Evidence also suggests that both in the early stages of plaque formation and late complications of cardiovascular disease fibrinogen has a major role [2].Major risk factors such as hypertension; cigarette smoking and hypercholesterolemia cannot fully explain the excess cardiovascular morbidity and mortality among diabetics. Extensive research activities are being paid to; disordered hemostatic mechanism in pathogenesis of both large vessel and small vessel disease in diabetes [3]. In Diabetic patient impaired glucose tolerance exerts an influence by enhancing thrombogenic factors such as; fibrinogen [4]. Several modifiable and nonmodifiable determinants like age; sex; smoking; body mass index (BMI); hypertension; alcoholism; glycemic control; lipid profile and urine albumin excretion rate determined the fibrinogen level[5-6].

Fibrinogen is the one of the most important coagulation protein in blood which is also acted for the precursor of fibrin and blood viscosity and platelet aggregation is mainly determined by concentration of plasma fibrinogen level. Because level of fibrinogen can be reduced considerably by life style modification; that also affect levels of established risk factors (such as regular exercise; smoking cessation; and moderate alcohol consumption); there is possibility that for disease prediction or prevention 
measurement (or modification) of fibrinogen may help in [7].

Plasma fibrinogen is one of the most important markers of inflammation and is also a potent prothrombotic factor responding endothelium tissues injury. Vascular changes due to inflammation and endothelial dysfunction used to indicate by level of fibrinogen. Fibrinogen as an acute phase protein has an important role in the pathogenesis of atherosclerosis and complication of atherothombosis disease. Elevated level of plasma fibrinogen is considered as an important risk factor for atherosclerotic vascular changes. Patient with noninsulin dependent diabetes mellitus (NIDDM) frequently have increased fibrinogen levels [8]. The entire coagulation cascade used to get disturbed and dysfunction in diabetes. Increased level of fibrinogen and plasminogen activator inhibitor I stimulates both thrombosis and defective dissolution of clot once formed. Increased level of fibrinogen in high risk patients with peripheral vascular disease indicate an increased risk of poor outcome; particularly for fatal cardiovascular morbidity and mortality [9]. For few decades; attention has been concentrated on fibrinogen; regarding its elevated role in the pathogenesis of cardiovascular risks in diabetic patients. Many extensive study even shown that thrombotic (smoking; low fruit/vegetable intake; fibrinogen and homocysteine) as well as atherosclerotic changes (hypertension; high fat diet; dyslipidemia) were important risk factors in premature coronary heart disease (CHD) [10]. Together with other haemostatic factors; fibrinogen may stimulate atherosclerotic changes and thrombosis through effects shown on platelet aggregation in vitro; blood viscosity and formation of foam cell. But till now; not extensive studies have been established a clear relationship between plasma fibrinogen levels as a low grade inflammatory markers and patients of NIDDM. The high prevalence as well as incidence of conventional coronary risk factors in patients with NIDDM not able to establish the proper explanation of increased cardiovascular-related morbidity and mortality in these patients. Fibrinogen may have a role in this excess risk. Fibrinogen is widely identified as a major independent risk factor of cardiovascular disease [11]. It is acting as one of the very important acute phase proteins and a positive marker of inflammation which are considered as predictive risk of myocardial infarction; stroke; peripheral arterial disease and sudden cardiac death. Plasma fibrinogen is also an important component of the coagulation cascade as well as a major determination factor of blood viscosity and flow of blood through vessels. Increasing proportion of suggestion from different epidemiological studies suggest that an increased risk of cardiovascular disorders including ischemic heart disease; stroke and others cardiovascular complication like thromboembolism are closely related with elevated plasma fibrinogen levels [12-13]. It has been shown that in diabetic patients high fibrinogen concentration enhances the risk of cardiovascular disease[14-16]. Insulin acutely increases fibrinogen production in an individual with NIDDM but not in individual without diabetes. There is significant correlation between fibrinogen level and fasting blood sugar level (FBS) [17].

The present study was undertaken to know the levels of fibrinogen in IDDM as well as in NIDDM patients and its relation with glycemic control. Diabetic patients have higher cardiovascular morbidity than non-diabetic individuals. Several studies have shown that haemostatic factor especially hyperfibrinogenemia is implicated as a source of atherosclerosis and its complications [18-19]. Studies have reported that fibrinogen levels were higher in diabetics than in controls. In view of above concepts and due to paucity of similar studies in Indian patients; this study had been undertaken to know the significance of fibrinogen as risk factor in NIDDM patients and its relation with glycemic control [20].

\section{Aims and Objectives}

\section{The aims of the present study are}

1. To detect the elevation of plasma level of fibrinogen; if any; in newly diagnosed untreated IDDM patients (group1); in newly diagnosed untreated NIDDM patients (group 2); NIDDM patients under treatment for at least five years(group3) and controls( group 4)

2. Compare the level of fibrinogen in above four groups of patients ( $\mathrm{p}$ value)

3. Correlation of glycemic status with fibrinogen level in above four groups of patients ( $\mathrm{r}$ value)

\section{Subjects and Methods}

Study design; inclusion and exclusion criteria:

Following four groups of subjects were selected for present study:

i) 12 newly diagnosed untreated insulin dependent diabetes mellitus (IDDM) patient

ii) 25 newly diagnosed untreated noninsulin dependent diabetes mellitus (NIDDM) patients within the age limit of 30-60 years

iii)25 NIDDM patients who are under treatment of oral hypoglycemic drugs for at least 5 yrs between the age limit of 30-60 yrs.

iv) 30 nondiabetic healthy controls.

Height and weight of all subjects were recorded and body mass index (BMI) was calculated. None of the ninety two volunteers were alcoholics or smokers. Patients of hypertension and ischemic heart disease were included in this study. Informed consent was taken from the individual subjects prior to blood collection. The study was undertaken in Kasturba Medical College; Mangalore; India and approved by institutional ethical committee.

\section{Fibrinogen assay}

\section{Principle}

Fibrinogen assay in plasma was carried out by Biuret method [21].Fibrinogen present in the plasma is converted to fibrin in presence of calcium chloride. The fibrin clot formed is collected and then digested with $\mathrm{NaOH}$. Protein content of the clot is determined using a red filter. 


\section{Procedure}

1. $0.5 \mathrm{ml}$ of plasma was mixed with $14 \mathrm{ml}$ of distilled water and $0.5 \mathrm{ml}$ of $2.5 \%$ calcium chloride solution in a small beaker and incubated at $37^{\circ} \mathrm{C}$ until a clot was formed. Then a glass rod was rotated to collect the clot on to it.

2. The rod was pressed against the side of the beaker to squeeze out any solution and to compress the clot. Care was taken to pick up any small piece of clot on the rod; which may have become detached and was dried by pressing carefully against a filter paper. Then it was transferred into a test tube into which the digestion was to be carried out.

3. After that; the clot was digested with $0.5 \mathrm{ml}$ of $0.1 \mathrm{~N} \mathrm{NaOH}$ in a boiling water bath. After cooling; $3.5 \mathrm{ml}$ of working Biuret reagent was added to the tube

4. The OD of the blue color developed was read at $555 \mathrm{~nm}$ after standing the tube in a water bath at $37^{\circ} \mathrm{C}$ for 5 minutes.

5. $0.5 \mathrm{ml}$ of standard protein solution $(800 \mathrm{mg} / \mathrm{dl})$ and $0.5 \mathrm{ml}$ of distilled water as blank were treated similarly.

\section{Calculation}

$$
\text { Concentration of fibrinogen }=\frac{\text { Absorption of sample }}{\text { Absorption of standard }} \times 800
$$

\section{Results}

Results should be discussed in (Table 1,2,3,4)

Table 1: The anthropometric data of the subjects participated in the study

\begin{tabular}{|c|c|c|c|c|}
\hline & $\begin{array}{c}\text { Group I(n=12) } \\
\text { (Mean } \pm \text { SD) }\end{array}$ & $\begin{array}{c}\text { Group II (n=25) } \\
\text { (Mean } \pm \text { SD) }\end{array}$ & $\begin{array}{c}\text { Group III (n=25) } \\
\text { (Mean } \pm \text { SD) }\end{array}$ & $\begin{array}{c}\text { Group IV(n=30) } \\
\text { (Mean } \pm \text { SD) }\end{array}$ \\
\hline Age (yrs) & $18.33 \pm 7.64$ & $48.22 \pm 7.11$ & $51.32 \pm 7.56$ & $44.97 \pm 15.06$ \\
\hline BMI & $19.50 \pm 1.23$ & $24.03 \pm 1.46$ & $24.20 \pm 2.40$ & $21.75 \pm 2.27$ \\
\hline
\end{tabular}

Table 2: The compare of mean value of fibrinogen and glycemic status in different groups.

\begin{tabular}{|c|c|c|c|c|}
\hline & $\begin{array}{c}\text { Group I } \\
\text { (Mean } \pm \text { SD) }\end{array}$ & $\begin{array}{c}\text { Group II } \\
\text { (Mean } \pm \text { SD) }\end{array}$ & $\begin{array}{c}\text { Group III } \\
\text { (Mean } \pm \text { SD) }\end{array}$ & $\begin{array}{c}\text { Group IV } \\
\text { (Mean } \pm \text { SD) }\end{array}$ \\
\hline Fibrinogen(mg/dl) & $434.65 \pm 46.36$ & $572.25 \pm 82.26$ & $581.74 \pm 79.09$ & $335.34 \pm 42.19$ \\
\hline RBS(mg/dl) & $338.25 \pm 50.97$ & $193.26 \pm 35.30$ & $93.61 \pm 33.65$ & $94.20 \pm 7.00$ \\
\hline
\end{tabular}

Table 3: Comparison of level fibrinogen ( $\mathrm{mg} / \mathrm{dl}$ ) between different groups in Table-3 ( $\mathrm{p}$ value $<0.05$ is considered significant.)

\begin{tabular}{|c|c|c|c|}
\hline Comparison between groups & Level(mg/dl) & Level(mg/dl) & p value \\
\hline Comparison between Group I and Group IV & $434.65 \pm 46.36(\mathrm{I})$ & $335.34 \pm 42.19(\mathrm{IV})$ & $<0.0001^{*}$ \\
\hline Comparison between Group II and Group IV & $572.25 \pm 82.26(\mathrm{II})$ & $335.34 \pm 42.19$ (IV) & $<0.0001^{*}$ \\
\hline Comparison between Group III and Group IV & $581.74 \pm 79.09(\mathrm{III})$ & $335.95 \pm 42.19$ (IV) & $<0.0001^{*}$ \\
\hline Comparison between Group I and Group II & $434.65 \pm 46.36(\mathrm{I})$ & $572.25 \pm 82.26$ (II) & $<0.0001^{*}$ \\
\hline Comparison between Group II and Group III & $572.25 \pm 82.26(\mathrm{II})$ & $581.74 \pm 79.09$ (III) & 0.682 \\
\hline
\end{tabular}

Table 4: Correlation of RBS with fibrinogen in all the groups ( $\mathrm{r}$ value).

\begin{tabular}{|l|c|c|c|}
\hline \multicolumn{1}{|c|}{ PARAMETERS } & GROUP I & GROUP II & GROUP III \\
\hline \multicolumn{1}{|c|}{ Fibrinogen } & 0.27 & -0.23 & -0.43 \\
\hline Group I = IDDM patients (newly diagnosed) & & & \\
Group II = NIDDM patients (newly diagnosed) & & \\
Group III = NIDDM patients (under treatment for at least 5 years) & \\
Group IV = Control \\
$\mathrm{n}=$ number of subjects \\
SD = Standard Deviation \\
BMI= Body Mass Index \\
RBS= Random Blood Sugar
\end{tabular}




\section{Statistics}

The data was analyzed by the students' $t$ test and the ANOVA test. Pearson's coefficient was applied for correlational analysis.

\section{Discussion}

NIDDM patients have a leading role in pathogenesis of inflammation; atherosclerosis; thrombogenesis and development of vascular complications and plasma fibrinogen is a low grade chronic inflammatory marker. For decades; irrespective of presence of diabetes mellitus; hemostatic factors especially fibrinogen has been considered as a cause for atherosclerotic change and its associated complications i.e.; MI; angina etc [22]. Fibrinogen used to plays an important role in development of atherosclerotic changes starting from the plaque formation upto formation of occlusive thrombus over a ruptured atherosclerotic plaque; which is considered to be very important cause of development of myocardial infarction (MI). By various mechanism by which fibrinogen promote atherosclerosis and formation of thrombus are hyperfibrinogenemia which increases plasma viscosity; it binds its receptors on platelet membrane leading to platelet aggregation; it induces reversible aggregation of erythrocytes; it forms fibrin and fibrinogen degradation products (FDPs) which in turn bind low density lipoprotein (LDL) and sequester more fibrinogen and fibrinogen with FDPs stimulate smooth cell proliferation and migration. All these factors result in increased atherogenesity in patients of hyperfibrinogenemia i.e.; diabetes and cause coronary artery disease. Besides; fibrinogen levels were found to be associated with age; smoking; hypertension (HTN); BMI; glycemic control and ischemic heart disease (IHD)[23].In the present study ; higher levels of fibrinogen were seen in patient with hypertension and ischemic heart disease (IHD) compared to without hypertension and IHD; however; difference in fibrinogen among cases and controls in those with hypertension was statistically highly significant and in those with IHD was statistically significant. The correlation between glycemic control and fibrinogen levels could be due to glycosylated fibrinogen is less susceptible to plasmin degradation and relative insulin deficiency in diabetics results in differential protein synthesis i.e.; $50 \%$ increase in fibrinogen synthesis and $29 \%$ decrease in albumin synthesis. Thus; a correlation between fibrinogen and atherosclerosis cannot be denied; it is the nature of association that is debatable-risk factor or risk marker. Several determinants of fibrinogen in health and disease are life style dependent; e.g. BMI; smoking etc.; and are amenable to change. The value of lowering fibrinogen levels by life style modifications or drugs is still unknown and future cardiovascular research in this area is warranted [24].

The aim of this study was to examine the level fibrinogen which is considered as an important inflammatory marker as a pathogenetic cause in NIDDM as well as IDDM patients. In our study; patients with DM had significantly higher fibrinogen level than controls. Similar results were obtained by previous studies [25-26] . Bembde AS et al[27] and Stec JJ et al [28] also found fibrinogen to be higher in diabetic patients than the control. They also showed fibrinogen to be higher in patients with coronary artery disease than without the disease. In the twelve newly diagnosed IDDM patients; the level of fibrinogen was found to be significantly increased as compared to control and finding is considered as statistically significant as $p$ value is found as $<0.0001 *$. Previous reports on the fibrinogen levels in IDDM are contradictory. Crooke MA et al [29] has shown that serum sialic acid and fibrinogen are not elevated in IDDM patients[30]. Gomes et al [30,31] reported increased level fibrinogen in IDDM patients. Increased fibrinogen levels; factor VII and whole blood viscosity was also found by John AD Elia et al [32] Similar results are reported by Defeo et al [33]. Plasma fibrinogen levels usually increased in NIDDM patients; thus suggesting that hyperfibrinogenemia could contribute to the excess cardiovascular morbidity and mortality in this disease [34-35]. However; the mechanisms leading to elevated level of fibrinogen concentration in NIDDM patients still not known. In particular; the hypothesis of fibrinogen synthesis as well as secretion in vivo is poorly understood; and they have never been directly investigated in NIDDM. Twenty-five NIDDM patients showed increased levels of fibrinogen in compare to control as denoted by significant $\mathrm{p}$ value $\left(<0.0001^{*}\right)$.The findings were matching with the opinion of most of the authors who worked with fibrinogen in NIDDM patients [36-38]. The role of chronic low grade inflammation in the pathogenesis NIDDM seems possible beyond doubt but at the same time its responsibility in IDDM cannot be totally ruled out. The course of the disease and resulting complications are similar in both NIDDM and IDDM. The most dreaded complication being that of development of atherosclerosis resulting in cardiovascular diseases. In the development of ischemic heart diseases fibrinogen is identified as an independent risk factor. Irrespective of the patients being NIDDM or IDDM; the risk of developing atherosclerosis remain the same. Hence there must be some mechanism which links the pathogenecity of NIDDM and IDDM. Barrazzani R et al [39] infused insulin to non-diabetics controls; NIDDM and IDDM and studied its role in fibrinogen production. Insulin replacement activity suppressed fibrinogen production in non diabetics and IDDM individuals. Fibrinogen production and its plasma concentration increased in NIDDM when euglycemia and euaminoaciduria were maintained. They postulated that an altered response to insulin causes hyperfibrinogenemia in NIDDM patients. If this hypothesis holds well; it doesn't explain hyperfibrinogenemia in IDDM where the basic pathology is insulin deficiency. Hence there must be some other factors which stimulate increased fibrinogen synthesis in IDDM patients contributing to cardiovascular disease risk. An insulin resistance syndrome score was developed which is on the basis of clinical risk factor in patient with IDDM and validated using euglycemic-hyperinsulinemic clamp studies. Fibrinogen levels were significantly associated with this insulin resistance syndrome score. This may explain high fibrinogen level in IDDM patients. But it still does not answer the above findings since the type subjects in this study were newly diagnosed. Hence the mechanism of increased fibrinogen synthesis needs to be proved further [40]. In this study; NIDDM patients with or without other cardiovascular diseases were found to have significantly higher levels of fibrinogen in comparison to nondiabetic control subjects. These variables also correlated with the vascular risk markers like age; blood pressure and blood glucose. 
However; this association was weak among NIDDM group which was possibly the result of very small sample size.

\section{Conclusion}

For centuries is was known to have the existence of two types of diabetes; IDDM; where the basic defect is an absolute insulin deficiency due to an autoimmune destruction of the $\beta$ cells and NIDDM ; where the basic pathology is decreased secretion of insulin or an elevated resistance of insulin by tissues which are insulin insensitive [30]. Then come the era of finding newer and newer mechanisms involved it the pathology. One that received wide acceptance and paved way for further research is the role low grade chronic inflammatory response and activated innate immunity in the pathogenesis of NIDDM and probably IDDM. In continuation with the ongoing research world over we tried to examine whether this hypothesis holds true by determination of level of fibrinogen as an inflammatory marker and whether the levels will be elevated or not. We can say with conviction that there is an activated innate immunity and a resultant increase in acute phase proteins in newly diagnosed NIDDM patients. Fibrinogen as an acute phase proteins was also significantly higher in the newly diagnosed IDDM patient also. Irrespective of oral hypoglycemic drug used for the treatment; treated group showed significantly lower acute phase protein levels comparable to the control group except fibrinogen levels. The observation of this present study supports the hypothesis that inflammation and inhibited fibrinolytic condition may play a basic pathogenetic role in NIDDM and its associated micro and macrovascular complications affected macro as well microvasculature of body Strong correlation between level of fibrinogen and glycemic status of the body also points to the fact that fibrinogen may be considered as an inflammatory marker in NIDDM. Proper understanding the dysglycemia-inflammation coagulation pattern may be useful in lowering the future cardiovascular risk in NIDDM.

\section{Acknowledgements}

This work was done under guidance and advice by $\mathrm{Dr}$ Poornima Manjrekar; Department of Biochemistry; Kasturba Medical College; Mangalore; India.

\section{References}

1. Dhawale S, Jayant S, Gupta A. Serum fibrinogen level in type 2 diabetes mellitus patients. Int J Adv Med. 2016;3(1):83-87. Doi: 10.18203/2349-3933.ijam20160194

2. Bruno G, Cavallo-perin P, Bargero G, Borra M, Errico ND, Pagano G. Association of fibrinogen with glycemic control and albumin excretion rate in patients with non-Insulin-dependent diabetes mellitus. Ann Intern Med. 1996;125(8): 653-657.

3. Fuller JH, Keen H, Jarrett RJ, Omer T, Meade TW, Charkrabarti R. Haemostatic variables associated with diabetes and its complications. Br Med J.1979;2(6196): 964-966.

4. Kannel BW, Wilson WF, Belanger AJ, Gagnon Dr, D"Agostino BD. Diabetes; fibrinogen; and risk of cardiovascular disease: the Framingham experience. JAMA. 1987;258(9):1183-1186
5. Anjula J, Gupta HL, Narayan S. Hyperfibrinogenemia in patients of diabetes mellitus in relation to glycemic control and urinary albumin excretion rate. JAPI. 2001;49:227-230.

6. Ernst E, Ludwig KR. Fibrinogen as a cardiovascular risk factor: a metaanalysis and review of literature. Ann Intern Med. 1993;118(12):956963.

7. Danish J, Simon G, Thompson D et al(Fibrinogen Studies Collaboration). Plasma fibrinogen level and the risk of major cardiovascular diseases and Nonvascular Mortality. J Amer Med Assoc 2005;294(14):17991809.

8. Doweik L, Maca T, Schillinger M, Budinsky A, Sabeti S, Minar E: Fibrinogen predicts mortality in high risk patients with peripheral artery disease: Eur J Vase Endovasc Surg. 2003; 26(4): 381-386.

9. Crook MA, Tutt P, Simpson H, Pickup JC: Serum sialic acid and acute phase protein in type 1 and type 2 diabetes. Clin Chim Acta. 1993;219(1-2):131-138.

10. Panwar RB, Gupta R. Atherothrombotic risk factors \& premature coronary heart disease in India: a case-control study. Indian J Med Res. 2011;134(1):26-32

11. Association of fibrinogen with cardiovascular risk factors and cardiovascular disease in the Framingham Offspring population. 2000;102(4):1634-1638

12. Meade TW, Mellows S, Brozovic M, Miller GJ,Chakrabarti RR, North WR, et al. Haemostatic function and ischemic heart disease: Principal results of the Northwick park heart study. Lancet. 1986;2(8506):533-537

13. Wilhelmsen L, Svardsudd K, Korsan-Bengtsen K,Larsson B, Welin L, Tibblin G. Fibrinogen as a risk factor for stroke and myocardiac infarction. N Engl J Med. 1984;311(8):501-505. Doi: 10.1056/ NEJM198408233110804

14. Christe M, Gattlen P, Fritschi J, lammle B, Berger W, Marbet A, et al. The contact phase of blood coagulation in diabetes mellitus and in patients with vasculopathy. Thromb Haemost. 1984;52(3):221-223.

15. Kannel WB, D'Agostino RB, Wilson PW, Belanger AJ, Gagnon DR. Diabetes; fibrinogen and risk of cardiovascular disease: the Framingham experience. Am Heart J. 1990;120(3):672-676.

16. Ganda OP, Arkin CH. Hyperfibrinogenemia; an important risk factor for vascular complications in diabetes. Diabetes care. 1992;15(10):1245-1250.

17. Pierpaolo DP, Gan MG, Haymond MW. Differential effect of insulin deficiency on albumin and fibrinogen synthesis in humans. J Clin invest.1991;88(3):833-840.

18. Wilhelmsen L, Suardsudd K, Kristoffer KB, Larson B, Lennart W, Jibblin G. Fibrinogen as a risk factor for stroke and myocardial infarction. N Engl J Med .1984,311(8): 501-505. Doi: 10.1056/ NEJM198408233110804

19. Thompson WD, Smith EB. Atherosclerosis and coagulation system. J Pathol. 1989,159(2):97-106. Doi: 10.1002/path.1711590203

20. Mittal S, Dwivedi RN, Lalchandani A, Puri A, Mishra P. Correlation of fibrinogen as an indicator of both long and short term glycemic control in diabetes. JAPI. 2002;50:129-130.

21. Varley H, Gowenlock AH, Bell M: Determination of plasma fibrinogen. In, Practical Clin Biochem CBS publishers and Distributors. 1991, 5th edition: 557-559. 
22. Bembde AS. A Study of Plasma Fibrinogen Level in Type-2 Diabetes Mellitus and its Relation to Glycemic Control. Indian J Hematol Blood Transfus 2012;28(2):105-108. Doi: 10.1007/s12288-011-0116-9

23. Brownlee M, Ulassara H, Cerami A. Nonenzymatic glycosylation reduces the susceptibility of fibrin to degradation by plasmin. Diabetes. 1983;32(7):680-684

24. Pierpaola DF, Margaret GG, Haymond MW. Differential effects of insulin deficiency on albumin and fibrinogen synthesis in humans. J Clin Invest.1991, 88(3):833-840. Doi: 10.1172/JCI115384

25. Kafle DR and Shrestha P. Study of fibrinogen in patients with diabetes mellitus. Nepal Med Coll J. 2010;12(1): 34-37.

26. Aslam M, Chandrasekhara P . Correlation of fibrinogen and HsCRP with microvascular complications of type 2 diabetes mellitus. Int J Health Sci Res. 2016;6(5):25-32.

27. Bembde AS. A study of plasma fibrinogen level in type-2 diabetes mellitus and its relation to glycemic control. Indian J Hematol Blood Transfus.2012;28(2):105-108.

28. Stec JJ, Silbershatz H, Tofler GH, Matheney TH, Sutherland P, Lipinska I, et al. Association of fibrinogen with cardiovascular risk factors and cardiovascular disease in the framingham offspring population. Circulation. 2000;102(14):1634-1638.

29. Crook MA, Tutt P, Simpson H, Pickup JC: Serum sialic acid and acute phase protein in type 1 and type 2 diabetes. Clin Chim Acta 1993,219(1-2):131-138

30. Shamim SM., Vivian D, Poornima M. Acute phase proteins in newly diagnosed diabetics. Biomed Res 2008;19(1):49-53

31. Gomes MB, Piccirilo LJ, Nogueira VG, Matos HJ : Acute phase proteins among patients with type1 diabetes: Diabetes Metab 2003;29(4):405411
32. Elia JAD, Weinrauch LA, Gleason RE, Lipinska I: Fibrinogen and factor VII levels improve with glycemic control in patients with type 1 diabetes mellitus who have microvascular complication. Arch Int Med. 2001;161(1):98-101

33. Defeo P, Volpi E, Lucidi P, Cruciani G, Reboldi G, Siepi D, et al. Physiological increments in plasma insulin concentration have selective and different effects on synthesis of hepatic proteins in normal humans: Diabetes 1993;42(7):995-1002.

34. Garcia MJ, McNamara PM, Gordon T, Kannel WB. Morbidity and mortality in diabetes in the Framingham population: sixteen year follow-up study. Diabetes. 1974;23(2):105-111.

35. Kannel WB, McGee DL. Diabetes and cardiovascular disease. The Framingham Study. JAMA. 1979:241(9):2035-2038.

36. Pickup JC: Inflammation and activated innate immunity in the pathogenesis of type 2 diabetes. Diabetes care 2004; 27(3):813-823.

37. McMillan DE: Increased levels of acute phase serum proteins in diabetes: Metabolism. 1989;38(11):1042-1046

38. Festa A, D’Agostino Jr R, Tracy RP, Haffner SM. Elevated levels of acute phase proteins and plasminogen activator inhibitor 1 predict the development of type 2 diabetes: the insulin resistance atherosclerosis study: Diabetes 2002;51(4):1131-1117

39. Barrazzani R, Kiwanuka E, Zanneti M, Cristini M. Insulin acutely increases fibrinogen production in individuals with type 2 diabetes but not in individuals without diabetes. Diabetes 2003;52(7):18511856

40. Williams KV, Erbey JR, Becker D, Arslanian S, Ochad TJ: Can clinical factors estimate insulin resistance in Type 1 diabetes: Diabetes 2000;49(4):626-632 